\title{
Effects of a Mineralized Human Cancellous Bone Allograft in Regeneration of Mandibular Class II Furcation Defects
}

\author{
Yi-Pin Tsao, ${ }^{*}$ Rodrigo Neiva, ${ }^{*}$ Khalaf Al-Shammari, ${ }^{\dagger}$ Tae-Ju Oh, ${ }^{*}$ and Hom-Lay Wang*
}

Background: A solvent-preserved, mineralized human cancellous bone allograft (MBA) was recently developed. However, its effect in regenerating furcation defects remains to be determined. Hence, the aim of the study is to evaluate the effects of this newly introduced MBA, with and without a bioabsorbable collagen membrane, for the treatment of mandibular class II furcation defects.

Methods: Thirty subjects with Hamp's Class II buccal or lingual furcation defects in lower molars were randomly assigned to open flap debridement (OFD), MBA, or MBA with a bioabsorbable collagen membrane (guided tissue regeneration [GTR] + MBA) groups. Clinical and defect measurements were obtained at the initial visit and at 6 -month reentry surgeries. The data were analyzed for intra- and intergroup comparisons and associations of treatment with probability of clinical improvement.

Results: Out of a total of 30 subjects, 27 individuals completed the study. Vertical bone fill (VBF) was $-1.6 \pm 2.1 \mathrm{~mm}$ in OFD, $1.9 \pm 1.4 \mathrm{~mm}$ in MBA, and $0.7 \pm 0.9 \mathrm{~mm}$ in GTR + MBA groups. VBF in MBA and GTR + MBA groups was significantly higher than that in the OFD group $(P<0.05)$. Horizontal bone fill (HBF) was $0.2 \pm 1.7 \mathrm{~mm}, 1.1 \pm 0.9 \mathrm{~mm}$, and $1.1 \pm$ $0.9 \mathrm{~mm}$ for OFD, MBA, and GTR + MBA groups, respectively. However, HBF, recession, clinical attachment level gain, and probing depth reduction at furcations showed no differences among groups.

Conclusions: Results obtained from this study indicate that solvent-preserved, mineralized human cancellous allograft, with or without collagen membrane, can significantly improve bone fill in mandibular Class II furcation defects. In addition, initial vertical defect depth was found to be the only factor that was associated with a higher probability of clinical improvement. J Periodontol 2006;77:416-425.

\section{KEY WORDS}

Allograft; debridement; furcation defect; guided tissue regeneration; membranes; regeneration.

\footnotetext{
* Department of Periodontics/Prevention/Geriatrics, School of Dentistry, University of Michigan, Ann Arbor, MI.

$\dagger$ Specialized Center for the Advancement of Dental Services, Ministry of Health, Kuwait.
}

A furcation defect has long been recognized as one of the most difficult treatments in periodontal therapy. Several non-surgical and surgical therapies have been suggested and attempted for managing this problem, but the results have been largely unpredictable. ${ }^{1-4}$ More recently, techniques aimed at using bone grafts and/or barrier materials have been evaluated in regenerating furcation defects. ${ }^{5,6}$ Encouraging results have been shown in some studies, ${ }^{7-10}$ but the ideal material to use has not been unequivocally validated. Allogenic bone graft materials have been advocated due to their availability and documented biologic activity. ${ }^{11,12}$ Mineralized solvent-dehydrated bone allograft $(M B A)^{\ddagger}$ is a graft which contains human mineralized component, organic matrix, and collagen. MBA is preserved by the Tutoplast process with solvent and low-dose gamma irradiation. Solventpreserved MBA is the only allograft that claims to preserve the trabeculation of the bony structure by the manufacturer and is shown to exhibit higher porosity and inner surface areas than freezedried bone allograft. ${ }^{13}$ Therefore, with the potential of improved properties for osteoconductivity, MBA has been introduced to periodontal therapy and recently has been evaluated for its use in regenerative and bone augmentation treatment. ${ }^{14,15}$ The objective of this randomized, examiner-masked, controlled study is to clinically evaluate the effects

‡ Puros, Zimmer Dental, Carlsbad, CA.

doi: 10.1902/jop.2006.050109 
of a mineralized bone allograft material in treating Class II furcation defects in mandibular molars.

\section{MATERIALS AND METHODS}

\section{Patient Population}

Thirty systemically healthy patients (mean age: 54.4 \pm 9.8 years; 12 females and 15 males) were recruited from the patient population of the University of Michigan, School of Dentistry from January 17, 2003 through July 20, 2004. Patient selection criteria for this study included the following: 1) systemically healthy; 2) $\geq 30$ years old; 3 ) patients who were willing to give informed consent and to attend the study; 4) patients who had a mandibular molar with Class II furcation involvement (Hamp's defect; ${ }^{1}$ horizontal loss of periodontal support $\geq 3$ but $\leq 7 \mathrm{~mm}$ ); 5 ) no use of antibiotic within 3 months prior to enrollment; 6 ) no known allergies to the materials used in the study; 7) patients must have completed initial phase of periodontal therapy; 8 ) ability to maintain good oral hygiene (O'Leary plaque score ${ }^{16} \leq 20 \%$ ); 9) width of keratinized tissue $\geq 1 \mathrm{~mm}$; and 10) the tooth had no mobility (Miller ${ }^{17}$ ) or mobility $\leq$ Class I. Patients with any of the following conditions were excluded from the study: 1) confirmed allergy to the graft material (confirmed by dermal patch skin test ${ }^{18}$ ); 2) previous history of periodontal regenerative therapy at the same site; 3 ) history of antibiotic treatment for medical or dental reasons within 3 months prior to enrollment; 4) pregnant females or those attempting to get pregnant; 5) clinically significant or unstable organic disease; 6) compromised healing potential, such as connective tissue disorders, heart murmurs, histories of rheumatic fever, valvular disease, or prosthetic joint replacement necessitating antibiotic prophylaxis; 7) active infectious disease, such as hepatitis, human immunodeficiency virus, or tuberculosis; 8) known metabolic bone disease (e.g., osteoporosis and rheumatoid arthritis); 9) taking steroid medications except for acute topical treatment; and 10) chronically treated (i.e., 2 weeks or more) with any medications known to affect periodontal status (e.g., phenytoin, calcium antagonist, cyclosporin, coumadin, and non-steriodal antinflammatory drugs) within 1 month of the screening examination. All other medications for chronic medical conditions were initiated at least 2 months prior to enrollment.

The use of human subjects in this study was approved by the Health Science Institutional Review Board of the University of Michigan. All subjects had reviewed and signed consent forms prior to entry in the study.

\section{Study Design}

This was a controlled, randomized, examiner-masked clinical trial with three parallel arms. The three arms of the study were as follows: a mineralized human can- cellous bone allograft (MBA) alone, MBA with collagen membrane (guided tissue regeneration [GTR] + MBA), and one control for open flap debridement (OFD) alone for treatment of Class II mandibular furcation defects. Presurgical treatments included oral hygiene instructions, scaling and root planing, and/ or occlusal adjustment as indicated. Subjects were required to complete baseline examinations and then randomly assigned into three groups during the surgery after defect debridement. The randomization was decided by drawing a piece of paper marked with either A, B, or C (10 of each) from a brown bag. Surgical procedures were either performed by or under the supervision of one clinician (YPT).

\section{Clinical Measurements}

Probing depth (PD), clinical attachment level (CAL), plaque index (PI; Silness and Lö ${ }^{19}$ ), gingival index $\left(\mathrm{GI} ; \mathrm{LÖ}^{20}\right)$, and bleeding on probing (BOP; score: no $=0$ and yes $=1$ ) were assessed at six sites (mesiobuccal, mid-buccal, disto-buccal, mesio-lingual, mid-lingual, and disto-lingual) for each study tooth at baseline and 6 months. Additional clinical measurements, such as horizontal probing depth (HPD) at furcation, were recorded at the time of initial surgery and at 6 -month reentry surgery. Changes in furcation status were assessed at 6 months after initial surgery. Direct defect measurement was performed using a prefabricated acrylic stent and a University of North Carolina (UNC) probe; the stent was grooved at the time of surgery to record the orientation of the probe. When the stent was placed on the occlusal surface of the tooth and adjacent teeth (Fig. 1), an occlusal ledge served as an occlusal landmark. The following measurements were included: stent to the free gingival margin, stent to the base of defect (SB), crest of bone to base of defect (CB), and bucco-lingual/ mesio-distal (BL/MD) morphology of the furcation defects (Fig. 1). The bucco-lingual depth of the defect was measured from the furcation entrance to the most inner part of the defect. The mesio-distal depth of the defect was measured at the crestal bone level. The wound healing index $\left(\mathrm{WHI}^{21}\right)$, to assess soft tissue healing, was recorded at 1 and 3 weeks and 3 and 6 months after surgery. WHI was recorded as the following criteria: score 1: uneventful wound healing with no gingival edema, erythema, suppuration, patient discomfort, or flap dehiscence; score 2: uneventful wound healing with slight gingival edema, erythema, patient discomfort, or flap dehiscence, but no suppuration; and score 3: poor wound healing with significant gingival edema, erythema, patient discomfort, flap dehiscence, or suppuration.

All measurements were performed by the same calibrated examiner (RN) using a UNC manual probe. The examiner remained masked to the treatment 


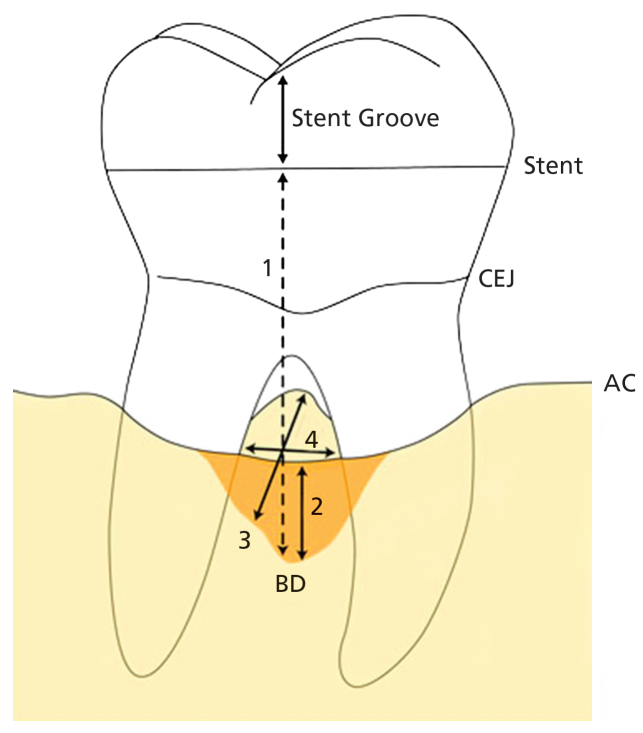

Figure I.

The method to measure the furcation defect during surgery: I) stent to the base of defect (BD); 2) alveolar crest (AC) to the base of defect; 3) HDD in bucco-lingual direction; and 4) HDW in mesio-distal direction. CEJ = cemento-enamel junction.

types of all patients for the entire duration of the study. Calibration was conducted prior to, during, and after the study to ensure adequate intraexaminer reliability. The $\kappa$ value of the examiner was $88 \%$ before the project had started, $89 \%$ during the project period, and $91 \%$ after the project was completed.

Vertical defect fill was calculated from the change of distances measured from the reference point on the stent to the base of defect. Crestal bone resorption was calculated by subtracting vertical bone fill from the change of defect depth.

\section{Surgical Protocol}

The surgical procedure included the elevation of a fullthickness mucoperiosteal flap with intracrevicular incisions with two vertical releasing lines, preserving as much keratinized tissue as possible without engaging the interdental papillae. The furcation defects were debrided, and all root surfaces were completely scaled and root planed by hand, ultrasonic, and rotating instrumentation. $\S$ Cemento-enamel projection was removed by enamel plastic burll if present. After debridement (Fig. 2), patients were randomized into one of the three groups: 1) MBA alone; MBA was mixed with normal saline and placed in the furcation area (Fig. 3); 2) GTR + MBA; after MBA placement, collagen membrane ${ }^{\text {Il }}$ was trimmed to cover the defect $2 \mathrm{~mm}$ beyond the edge of furcation defect; and 3) OFD alone; all surgical procedures were identical except that no bone graft or membrane was placed. The membrane was sutured with 5-0 chromic gut sutures ${ }^{\#}$ using the sling suture technique. The flap was sutured

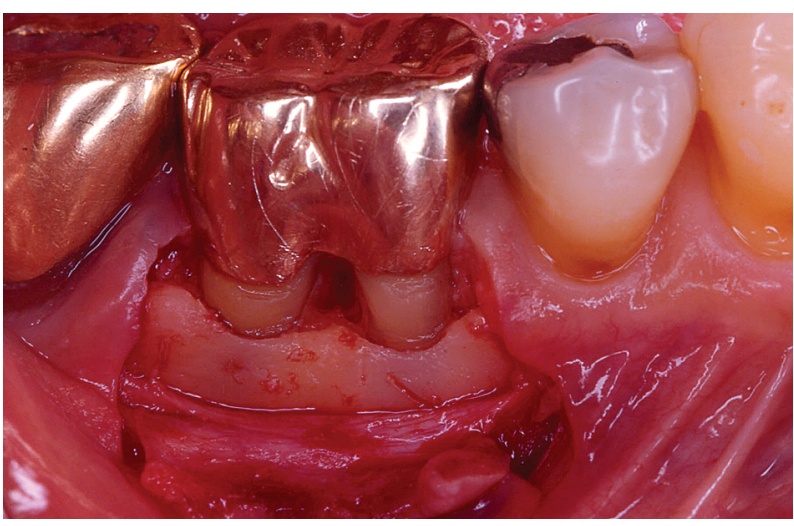

Figure 2.

Debridement of the furcation defect.

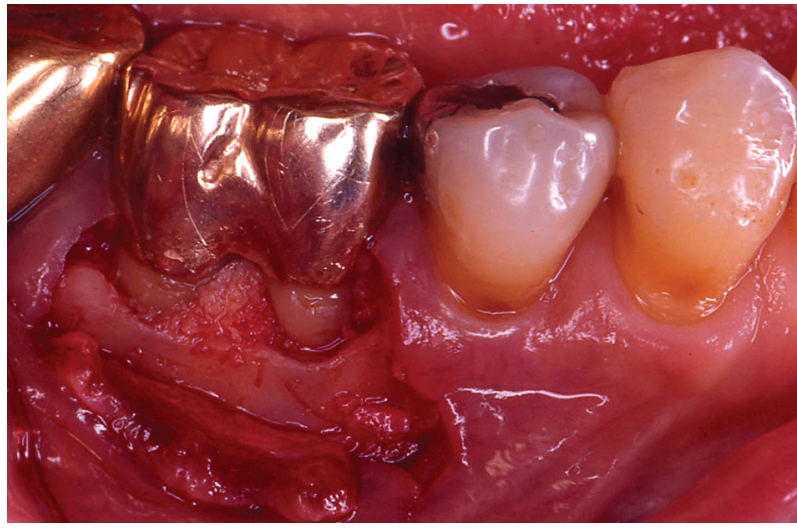

Figure 3.

Mineralized bone allograft in place.

securely to its original position with $5-0$ polyglactin $910,{ }^{* *}$ with care to ensure that no bone graft or membrane was left exposed. In the OFD-treated sites, the furcations were covered by repositioning the flaps. None of the furcations were exposed after treatment.

\section{Postoperative Care}

All patients received routine, written, and oral postoperative instructions and were instructed to rinse with $0.12 \%$ chlorhexidine gluconate for a period of 3 to 4 weeks. Sutures were removed 7 to 10 days after surgery. Patients returned in 3 weeks after surgery for observation of any adverse tissue reactions. All patients received periodontal maintenance at 3 and 6 months.

\section{6-Month Reentry Surgery}

At the end of 6 months, the patients were scheduled for reentry surgeries. Clinical measurements (GI, PI,

\footnotetext{
$\S$ Nemeyer's bur, Brasseler USA, Small Parts, Miami Lakes, FL.

Brasseler USA, Small Parts.

If BioMend Regular, Zimmer Dental, Carlsbad, CA.

\# Ethicon, Johnson \& Johnson, Somerville, NJ.

** Vicryl, Ethicon, Johnson \& Johnson.
} 
vertical probing depth [VPD], CAL, WHI, HPD, stent to the free gingival margin, SB, CB, BL/MD morphology of defect, and mobility) of the involved tooth were recorded. The incisional design was the same as the initial surgery. In patients with other periodontal problems in the same quadrant, a full quadrant periodontal surgery was performed as indicated. Full-thickness mucoperiosteal flaps were reflected to expose the previously treated furcation areas for clinical measurements as previously described. Patients were seen 1 week after surgery for suture removal and then placed on a closely supervised schedule for periodontal maintenance.

\section{Statistical Analysis}

Power calculations (a mean difference of $0.667^{18}$ was used in the calculation) were performed before the study was initiated. To achieve $80 \%$ power and detect mean differences of the clinical parameters between groups, 10 subjects in each group were required. The data collected on continuous variables were presented as mean \pm SD for different groups and analyzed using a statistical software program. ${ }^{\dagger \dagger}$

The paired $t$ test and Wilcoxon signed rank test were used to analyze continuous parameters, i.e., VPD, HPD, and CAL, before and after treatment within the groups. The Wilcoxon signed rank test was applied to compare discrete parameters, i.e., PI, GI, and WHI, at different time points within the groups. The paired $t$ test and repeated measures analysis of variance (ANOVA) were used to compare the three groups in terms of mean differences over time on the various measures collected at baseline and 6 months (e.g., VPD and CAL). The repeated measures ANOVA were used to compare the three groups in terms of mean differences over time on the various measures collected during surgery (first and second surgeries). The KruskalWallis test and general linear models (GLM) ANOVA were used to compare the mean of clinical parameter improvement over time (e.g., percentage of improvement in vertical defect depth (VDD) and millimeters of improvement in VDD) between different treatment groups. The paired $t$ test and repeated measures ANOVA were used to compare the three groups in terms of the mean difference of clinical measurements (e.g., horizontal defect depth [HDD]-BL, VDD, CAL, and VPD) over time (baseline and 6 months). All tests of hypotheses were two-sided, and differences were considered statistically significant when $P<0.05$ with a $95 \%$ level of confidence.

\section{RESULTS}

\section{Demographic Results (Table 1)}

Out of a total of 30 subjects, 27 patients (12 females and 15 males; mean age: $54.4 \pm 9.8$ years) completed the study. A total of 21 buccal and six lingual furca- tions (four in OFD and two in MBA groups) in mandibular molars (22 first molars and five second molars) were treated. The distribution of tooth type was similar among groups.

\section{Baseline Measurements}

There were no statistically significant differences of baseline clinical parameters among the groups $(P>0.05)$ (Tables 2 through 5).

\section{Intragroup Comparisons}

No serious postoperative complications were reported or observed throughout the entire study. Six months after initial surgery, the reduction of VPD was statistically significant in the MBA group $(P<0.05)$ and marginally significant in the GTR + MBA group $(P=0.08)$ (Table 2). The reduction of HPD was statistically significant in the GTR + MBA group $(P<0.05)$ and marginally significant in the MBA group $(P=0.07)$. The mean difference of CAL showed no significant difference in any group over time. The GI decreased in all groups compared to baseline $(P<0.05)$ (Table 3$)$. The PI and BOP did not show statistically significant differences in any group over time. The reductions of HDD and vertical bone fill were statistically significant in the MBA and GTR + MBA groups $(P<0.05)$ (Tables 4 and 5). The horizontal defect width (HDW) decreased significantly only in the MBA group $(P<0.05)$ (Table 4). No statistically significant difference of WHI between any two time points was found.

\section{Intergroup Comparisons}

At the 6-month follow-up, six out of 27 patients (22.2\%) had converted to Class I furcations, whereas others remained Class II (Table 6). The remaining vertical defect depth measured at reentry was $1.0 \mathrm{~mm}$ in the MBA group, $1.6 \mathrm{~mm}$ in the GTR + MBA group, and $3.0 \mathrm{~mm}$ in the OFD group (Table 5). However, no statistical difference was noted among groups. Similarly, no differences in crestal bone resorption among groups were found (Table 5). The remaining HDD at reentry was $4.6 \mathrm{~mm}$ in the OFD group and $3.2 \mathrm{~mm}$ in the MBA and GTR + MBA groups, with no statistically significant differences (Table 4). A similar result was also found in the HDW (Table 4).

When examining the vertical bone fill (Fig. 4), the MBA and the GTR + MBA groups showed significant improvement, whereas the OFD group had a loss of vertical bone height (Table 5). A statistically significant difference was found between the MBA and OFD groups $(P<0.05)$ and between the GTR + MBA and the OFD $(P<0.05)$ groups with regard to vertical bone fill (Table 5). When comparing the vertical bone fill in percentage, the MBA group had a significantly higher percentage of vertical bone fill than the OFD group $(48.9 \%$ versus $5.6 \%$, respectively; $P<0.05)$.

$\dagger \dagger$ SPSS version 12.0, SPSS, Chicago, IL. 
Table I.

\section{Baseline Demographic Results}

\begin{tabular}{lcccc}
\hline & Total $(\mathrm{N}=27)$ & OFD $(n=9)$ & $\mathrm{MBA}(\mathrm{n}=9)$ & $\mathrm{GTR}+\mathrm{MBA}(\mathrm{n}=9)$ \\
\hline Age (years) (mean \pm SD [range]) & $54.4 \pm 9.8(30$ to 77$)$ & $48.8 \pm 3.1(30$ to 65$)$ & $57.7 \pm 3.1(42-77)$ & $56.7 \pm 3.1(43-69)$ \\
Gender* & $\mathrm{F}=12$ & $\mathrm{~F}=5$ & $\mathrm{~F}=3$ & $\mathrm{~F}=4$ \\
& $\mathrm{M}=15$ & $\mathrm{M}=4$ & $\mathrm{M}=6$ & $\mathrm{M}=5$ \\
Location of furcation $^{\dagger}$ & $\mathrm{B}=21$ & $\mathrm{~B}=5$ & $\mathrm{~B}=7$ & $\mathrm{~B}=9$ \\
& $\mathrm{~L}=6$ & $\mathrm{~L}=4$ & $\mathrm{~L}=2$ & $\mathrm{~L}=0$ \\
Tooth $^{\ddagger}$ & $\mathrm{FM}=22$ & $\mathrm{FM}=7$ & $\mathrm{FM}=8$ & $\mathrm{FM}=7$ \\
& $\mathrm{~S}=5$ & $\mathrm{~S}=2$ & $\mathrm{~S}=1$ & $\mathrm{~S}=2$ \\
\hline
\end{tabular}

* $\mathrm{F}=$ female; $M=$ male.

$\dagger \mathrm{B}=$ buccal; $\mathrm{L}=$ lingual.

‡ $\mathrm{FM}=$ first molar; $\mathrm{S}=$ second molar.

\section{Table 2.}

\section{Clinical Measurements at Furcation Site (mean \pm SD [mm])}

\begin{tabular}{lccccccccc}
\hline & \multicolumn{4}{c}{ VPD } & \multicolumn{3}{c}{ HPD } & \multicolumn{3}{c}{ CAL } \\
\cline { 2 - 9 } Group & Baseline & 6 Months & Difference & Baseline & 6 Months & Difference & Baseline & 6 Months & Difference \\
\hline OFD & $4.7 \pm 0.9$ & $4.5 \pm 0.9$ & $-0.1 \pm 1.1$ & $4.7 \pm 1.7$ & $3.8 \pm 1.6$ & $-0.9 \pm 1.9$ & $5.4 \pm 1.3$ & $6.3 \pm 1.8$ & $0.9 \pm 1.6$ \\
MBA & $4.3 \pm 1.8$ & $3.4 \pm 1.4$ & $-0.9 \pm 0.9^{*}$ & $3.9 \pm 1.1$ & $2.7 \pm 1.4$ & $-1.2 \pm 1.9^{\dagger}$ & $5.1 \pm 2.8$ & $5.0 \pm 1.9$ & $-0.1 \pm 1.0$ \\
GTR + MBA & $4.6 \pm 1.1$ & $3.9 \pm 1.5$ & $-0.7 \pm 1.0^{\ddagger}$ & $4.2 \pm 1.2$ & $3.1 \pm 1.2$ & $-1.1 \pm 0.5^{*}$ & $5.2 \pm 2.0$ & $5.6 \pm 2.4$ & $0.3 \pm 1.2$ \\
\hline
\end{tabular}

* Statistically significant, $P<0.05$; Wilcoxon signed rank test.

$\dagger$ Borderline significance, $P=0.07$; Wilcoxon signed rank test.

\# Borderline significance, $P=0.08$; Wilcoxon signed rank test.

Table 3.

Clinical Parameters at Furcation Sites (mean \pm SD)

\begin{tabular}{lccccccccc}
\hline & \multicolumn{3}{c}{ Gl } & \multicolumn{3}{c}{ Pl } & \multicolumn{3}{c}{ BOP } \\
\cline { 2 - 9 } Group & Baseline & 6 Months & Difference & Baseline & 6 Months & Difference & Baseline & 6 Months & Difference \\
\hline OFD & $1.7 \pm 0.5$ & $0.3 \pm 1.5$ & $-1.3 \pm 0.5 *$ & $1.1 \pm 0.8$ & $1.0 \pm 0.5$ & $-0.1 \pm 0.8$ & $1.0 \pm 0.0$ & $0.7 \pm 0.5$ & $-0.3 \pm 0.5$ \\
MBA & $1.6 \pm 0.5$ & $0.7 \pm 0.7$ & $-0.9 \pm 0.6 *$ & $0.9 \pm 0.6$ & $1.0 \pm 0.7$ & $0.1 \pm 1.2$ & $0.8 \pm 0.4$ & $0.4 \pm 0.5$ & $-0.3 \pm 0.5$ \\
GTR + MBA & $1.4 \pm 0.7$ & $0.3 \pm 0.7$ & $-1.1 \pm 0.9 *$ & $1.0 \pm 0.9$ & $0.6 \pm 0.7$ & $-0.4 \pm 1.4$ & $0.9 \pm 0.3$ & $0.6 \pm 0.5$ & $-0.3 \pm 0.7$ \\
\hline
\end{tabular}

* Statistically significant, $P<0.05$; Wilcoxon signed rank test.

However, no difference was noted between the GTR + MBA and the OFD groups (38.3\% versus $5.6 \%$, respectively) (Table 7). The horizontal bone fill was $0.2 \pm 1.7 \mathrm{~mm}(14.7 \pm 19.7 \%)$ in the OFD group, 1.1 $\pm 0.9 \mathrm{~mm}(24.6 \pm 21.4 \%)$ in the MBA group, and $1.1 \pm 0.9 \mathrm{~mm}(23.9 \pm 17.2 \%)$ in the GTR + MBA group, with no statistically significant differences noted among groups (Tables 4 and 8 ). The recession and
CAL improvement at furcation showed no significant differences among groups.

\section{Correlation of HPD and HDD}

Measurements (Table 9)

The correlations between HPD prior to surgery and open HDD measurements during surgeries (both initial and reentry) were analyzed. The correlation was 
Table 4.

\section{Defect Measurements During Surgeries (mean \pm SD [mm])}

\begin{tabular}{lllllll}
\hline & \multicolumn{3}{c}{ HDD } & \multicolumn{3}{c}{ HDW } \\
\cline { 2 - 7 } Group & Baseline & 6 Months & Difference & Baseline & 6 Months & Difference \\
\hline OFD & $4.7 \pm 1.4$ & $4.6 \pm 1.6$ & $0.2 \pm 1.7$ & $3.4 \pm 0.5$ & $3.4 \pm 0.7$ & $0.0 \pm 0.5$ \\
MBA & $4.3 \pm 0.8$ & $3.2 \pm 1.0$ & $1.1 \pm 0.9 *$ & $3.7 \pm 0.7$ & $3.0 \pm 0.5$ & $-0.7 \pm 0.7 *$ \\
GTR + MBA & $4.4 \pm 1.4$ & $3.2 \pm 1.1$ & $1.1 \pm 0.9 *$ & $3.2 \pm 0.4$ & $3.0 \pm 0.7$ & $-0.2 \pm 0.8$ \\
\hline
\end{tabular}

* Statistically significant, $P<0.05$; Wilcoxon signed rank test.

Table 5.

Vertical Bone Level Measurements During Surgery (mean \pm SD $[\mathrm{mm}]$ )

\begin{tabular}{lcc}
\hline \multicolumn{2}{c}{ Baseline } & 6 Months \\
\hline Crest of bone to base of defect & \\
OFD & $2.9 \pm 1.3$ & $3.0 \pm 2.3$ \\
MBA & $4.0 \pm 1.0$ & $1.0 \pm 1.6$ \\
GTR + MBA & $2.8 \pm 1.8$ & $1.6 \pm 1.9$ \\
Vertical bone fill* & \\
OFD & $-1.6 \pm 2.1]+]$ \\
MBA & $1.9 \pm 1.4]+$ \\
GTR + MBA & $0.7 \pm 0.9$ \\
Crestal bone resorption & \\
OFD & $1.4 \pm 1.4$ \\
MBA & $1.3 \pm 1.1$ \\
GTR + MBA & $0.7 \pm 0.9$ \\
\hline
\end{tabular}

* Results of Kruskal-Wallis test: There is evidence of a significant difference of the mean of vertical bone fill between MBA and OFD $(P=0.002)$ and between GTR + MBA and OFD $(P=0.016)$.

$\dagger$ Statistically significant, $P<0.05$.

Table 6 .

\section{Distribution of Furcation Closure at 6 Months}

\begin{tabular}{cccc}
\hline & OFD & MBA & GTR + MBA \\
\hline Class 0 & 0 & 0 & 0 \\
Class I & 1 & 3 & 2 \\
Class II & 8 & 6 & 7 \\
Class III & 0 & 0 & 0 \\
\hline
\end{tabular}

0.80 at baseline and 0.77 at 6 months. No significant difference between HPD and HDD was found at baseline $(4.2 \pm 1.3 \mathrm{~mm}$ versus $4.5 \pm 1.2 \mathrm{~mm}$, respectively, $P>0.05)$. However, at 6 months, the measurement of HPD was significantly lower than HDD (3.2 \pm $1.4 \mathrm{~mm}$ versus $3.7 \pm 1.4 \mathrm{~mm}, P<0.05)$. This implied that bone sounding is more accurate in diagnosing furcations prior to surgery than after treatment.

\section{DISCUSSION}

Methods for the treatment of furcation-involved molars have shown varying degrees of success. ${ }^{7-10}$ Limited information is available with regard to the use of solventpreserved human MBA as bone replacement material for the treatment of furcation defects. The benefit of a bioabsorbable membrane (e.g., collagen membrane) in treating Class II furcation defects over OFD has been reported. ${ }^{7-9,18,22}$ Nevertheless, data were lacking when examining the effects of MBA with or without bioabsorbable collagen membrane for management of Class II furcation defects. Therefore, the purpose of this study was aimed at evaluating the capability of MBA with and without bioabsorbable collagen membrane for regenerating mandibular Class II furcation defects. A historical study performed at the University of Michigan that compared bioabsorbable collagen membrane alone to OFD in treating Class II furcations was used as a historical control for the collagen membrane alone group. ${ }^{18}$

Results obtained from this study indicated the positive effects of MBA and GTR + MBA for the treatment of furcation defects, especially vertical defect fill. The improvement of vertical bone level was significant in the MBA ( $1.9 \mathrm{~mm})$ and GTR + MBA $(0.7 \mathrm{~mm})$ groups, whereas the OFD group lost $1.6 \mathrm{~mm}$ of vertical height. In a study using collagen membrane in treating furcations, similar vertical bone fill $(0.7 \mathrm{~mm})$ in a GTR group was found. ${ }^{23}$ The differences between the MBA and OFD, GTR + MBA, and OFD groups in vertical bone fill were clinically significant because it was more than standard deviation of probe measurement. Similar findings were also reported by Kenney et al. ${ }^{24}$ when porous hydroxylapatite was used as a grafting material in treating Class II furcations (a $2.0-\mathrm{mm}$ gain of vertical fill in bone graft sites versus a $0.3-\mathrm{mm}$ loss of height in OFD sites). The effect of bone replacement graft (BRG) with demineralized freeze-dried bone allograft (DFDBA) and citric acid in treating Class II furcations reported by Gantes et al. ${ }^{25}$ showed a similar vertical bone fill of $2.4 \mathrm{~mm}$. Our data were also in agreement with Couri et al. ${ }^{26}$ However, several studies demonstrated minimal bone fill only, ranging from 0.1 to $0.4 \mathrm{~mm}$, in the BRG or GTR or BRG + GTR groups. ${ }^{27-29}$ Different membranes (e.g., collagen membrane in this study) or bone grafts (e.g., mineralized human cancellous bone) used may explain the 


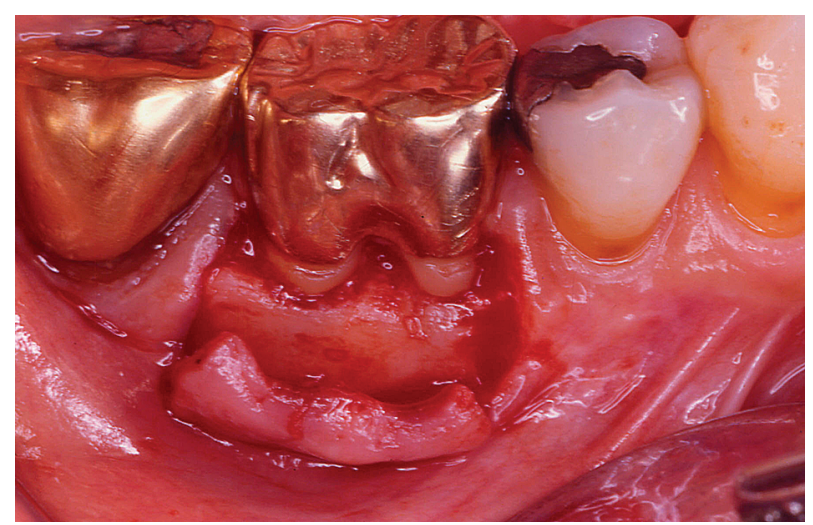

Figure 4.

Bone fill in furcation was observed.

Table 7.

Vertical Bone Fill (\%) and Comparison Among Treatment Groups

\begin{tabular}{|c|c|c|c|c|}
\hline Group & Mean \pm SD (\%) & $0 \%$ to $25 \%$ & $26 \%$ to $50 \%$ & $>50 \%$ \\
\hline OFD & $5.6 \pm 16.7$ & 8 & । & 0 \\
\hline MBA* & $48.9 \pm 34.1$ & 3 & 4 & 2 \\
\hline $\mathrm{GTR}+\mathrm{MBA}$ & $38.3 \pm 40.9$ & 5 & । & 3 \\
\hline
\end{tabular}

* Results of Kruskal-Wallis test: $x^{2}(2)=9.160 ; P=0.010$; results of GLM ANOVA: $P=0.026$ when comparing MBA to OFD. There is evidence of a significant difference of the mean of vertical bone fill between MBA and OFD.

different results obtained. Mineralized human cancellous allograft retains the mineral, collagen structures, and trabecular patterns of the bone. These characteristics, with the high porosity and increased inner surfaces on the grafts, may facilitate osteoconductivity beyond other bone graft materials. Therefore, the higher amount of bone formation could be observed when MBA is used. Additional placement of collagen membrane over MBA could promote PDL fibroblast and osteoblast cell adhesion and enhance periodontal regeneration via collagen membrane hemostatic and chemotactic function. ${ }^{30}$ This may explain the positive results obtained in the GTR + MBA group. It is not surprising to note that OFD treatment resulted in a loss of vertical bone $(1.6 \mathrm{~mm}$ in our study, and others have shown 0.2 to $1.0 \mathrm{~mm}$ of bone loss)..$^{28,31}$ This is further supported by the evidence that showed crestal bone loss is often unavoidable after a full-thickness flap reflection. ${ }^{32,33}$ Due to the furcation defect morphology (it is always surrounded by two roots), this implies 1 - or 2-wall osseous defects for most furcation defects. These types of bony defects do not favor bone fill after OFD. Although several studies suggested that the combination of BRG and GTR provided the best
Table 8.

\section{Horizontal Bone Fill (\%) and Comparison Among Treatment Groups}

\begin{tabular}{|c|c|c|c|c|}
\hline Group & Mean \pm SD (\%) & $0 \%$ to $25 \%$ & $26 \%$ to $50 \%$ & $>50 \%$ \\
\hline OFD & $14.7 \pm 19.7$ & 7 & 2 & 0 \\
\hline MBA & $24.6 \pm 21.4$ & 7 & I & I \\
\hline $\mathrm{GTR}+\mathrm{MBA}$ & $23.9 \pm 17.2$ & 5 & 4 & 0 \\
\hline
\end{tabular}

There was no statistically significant difference among groups; results of Kruskal-Wallis test: $\chi^{2}(2)=1.146 ; P=0.564$

\section{Table 9.}

\section{Comparison of HPD and HDD}

\begin{tabular}{cccc}
\hline & Mean \pm SD $(\mathrm{mm})$ & Correlation* $^{*}$ & $P$ Value* \\
\hline HPD-I & $4.2 \pm 1.3$ & 0.80 & 0.109 \\
HDD-1 & $4.5 \pm 1.2$ & & \\
HPD-2 & $3.2 \pm 1.4$ & 0.77 & $0.013^{\dagger}$ \\
HDD-2 & $3.7 \pm 1.4$ & & \\
\hline
\end{tabular}

1 = measurement at initial surgery; 2 = measurement at reentry.

* Based on paired sample $t$ test.

$\dagger$ Statistically significant, $P<0.05$.

results in furcation treatment, ${ }^{34-37}$ some have also questioned the advantage of using this combination approach. ${ }^{29}$ As discussed in recent systematic reviews, ${ }^{9,10}$ it is not possible to compare the outcomes from different barrier and grafting materials due to the limited controlled clinical trials available.

There were three dropouts in the present study, and they were equally distributed, one subject from each group. This was indicated and described in Table 1 (as illustrated, the final subject number was nine in each group). Future studies are encouraged to add $10 \%$ more subjects to accommodate the potential patient dropout. Although there were different teeth treated and locations (buccal versus lingual) of furcations, no statistical difference was found when comparing these variables (first versus second molars; buccal versus lingual furcation defects). The location of furcation defects may influence the ability of patients to clean these areas. However, when data were analyzed, no difference in plaque index (index to assess the hygiene ability of patients) was found, which indicated that the location of furcation did not influence the ability of patients to clean the area.

When comparing the outcome of the study to the historical GTR study, ${ }^{38}$ there was a significant difference between the results reported in the control groups. Vertical bone fill in the OFD group was 1.5 
$\mathrm{mm}$ and $2.5 \mathrm{~mm}$ in the GTR alone group from the historical study. ${ }^{38}$ Due to the variation of outcomes obtained in our control group, it was impossible to use the historical data to compare the outcome to the present study. Therefore, no comparisons were attempted to differentiate the outcome differences among the GTR, MBA, and GTR + MBA groups.

The present study also demonstrated a horizontal bone fill of $1.1 \mathrm{~mm}$ in the MBA and GTR + MBA groups, whereas it was only $0.2 \mathrm{~mm}$ in the OFD group. This is in agreement with early studies that showed minimal horizontal bone fill after treatment in furcation defects. ${ }^{27,28,39}$ Our data also supported the data reported by Kenney et al., ${ }^{24}$ who demonstrated a 1 -mm horizontal bone fill in a BRG group. ${ }^{24}$ Furthermore, the horizontal bone fill in a recent study using GTR + BRG illustrated a similar percentage of horizontal bone fill compared to ours (23.8\% versus $23.9 \%) .{ }^{26}$ From the systematic review by Jepsen et al., ${ }^{9}$ the mean difference of horizontal defect fill between the GTR and OFD groups was $0.87 \mathrm{~mm}$ when combined with mandibular and maxillary molars; however, it was $1.51 \mathrm{~mm}$ when only mandibular molars were included. The outcome of the present study was slightly less favorable but close to results reported in the metaanalysis.

The lack of sufficient bone formation to fill any of the furcation defects indicated the low predictability of the procedure. This agrees with the majority of studies that showed inconsistency of complete furcation closures. ${ }^{7,9,40}$ From the recent systematic review, ${ }^{9}$ only one case out of eight reentry studies showed complete furcation fill among cited randomized controlled trials of GTR in furcations. Furthermore, one recent study showed three out of 45 GTR treated cases had complete furcation closure in 14 months. ${ }^{41}$ Nonetheless, complete furcation closure was reported by studies using clinical measurements (e.g., PD and CAL). ${ }^{42}$ The inconsistency noted between clinical and reentry measurement may explain this difference. ${ }^{39}$ New connective tissue attachment may form without a concomitant buildup of the alveolar bone. ${ }^{39,43}$ Those studies indicated that bone changes at furcations cannot be properly assessed without reentry, and conclusions drawn from clinical measurements of gingival recession, probing depth, and attachment level may be problematical. ${ }^{39}$ In the current study, no furcation was completely filled with bone, and a horizontal component of the bone lesion was always present at reentry. If complete bone fill of a furcation is considered the goal of regenerative treatment, then the procedure was not successful in any single case. On the other hand, the study demonstrated that partial bone regeneration is possible. To what extent such partial gain promotes the longevity of the tooth remains to be studied.
The accuracy of the clinical diagnosis of the furcations has been debated from different studies. It was reported to be overestimated and inaccurate in some studies. ${ }^{36,44}$ The results from this study suggested that furcation diagnosis with bone sounding can accurately estimate bone levels as determined at the time of surgery in the inflamed periodontal tissue. Studies using clinical probing to conclude furcation closure might lead to an overestimation of the clinical outcome by feeling resistance of the reattachment, new attachment, or even granulation tissues instead of true bone fill.

There was a significant reduction of vertical probing depth $(0.9 \mathrm{~mm})$ in the MBA group at 6 months compared to baseline. Although the GTR + MBA and OFD groups also had minimal VPD reduction, no statistically significant difference was noted. This is less favorable than the conclusion from the systematic review reported by Murphy and Gunsolley, ${ }^{8}$ which showed GTR had more reduction in vertical probing depth compared to OFD controls. But our data in the GTR + MBA group are similar to the results of the study by Couri et al. ${ }^{26}$ Data obtained in this study are also in agreement with Andersson et al. ${ }^{45}$ and Cury et al.;22 changes of vertical CAL at furcation sites between baseline and 6 months were not statistically significant in all groups. All groups in our study showed improvement in HPD. However, the improvement was statistically significant only in the GTR + MBA group $(P<0.05)$ and was marginally significant in the MBA group $(P=0.07)$. No specific conclusion regarding the improvement of HPD could be drawn from the recent systematic reviews, due to the heterogeneity among the studies cited. ${ }^{8,10}$ Nonetheless, our data are similar to those from previous studies by Caffesse et al. ${ }^{27}$ and Black et al. ${ }^{46}$ in the GTR and OFD groups.

The wound healing index was developed by our group to assess soft tissue healing after periodontal/ implant surgery. The index is designed to quantitate the soft tissue response. It has been shown to be a reliable index for assessing soft tissue response after surgery. ${ }^{21}$ Slight edema means a slightly greater swelling than the normal knife-edge tissue. Significant edema means an obvious swelling. The score is designed for assessing soft tissue response; slight dehiscence and slight edema were grouped into the same score.

Adverse tissue reaction or infection was not observed following any of the surgical procedures in the study. The bone graft material and bioabsorbable collagen membrane used in the study appear to be biocompatible and safe. Membrane exposure was not observed in any of the cases in the study. This may be explained by the biocompatibility of the collagen membrane and its hemostatic and chemotactic functions. ${ }^{47-50}$ The hemostatic function will enhance 
early wound stabilization and clot formation. This indirectly promotes better flap adaptation, thus resulting in less membrane exposure. Furthermore, the chemotactic function of the collagen membrane promotes fibroblast migration that ensures primary wound coverage can be facilitated.

A major question was whether partial improvement in mandibular Class II furcations, such as shown in this study and others, ${ }^{7}$ improves the prognosis of the tooth. Higher chances of bone fill were found in moderate defects, rather than deep Class II defects in this study. Similar trends were also reported by others. ${ }^{29,42}$ However, the treatment outcome facilitating the ability of patients to perform better plaque control or the ability of clinicians to maintain the tooth remains undecided. The outcome of the present study indicates that regenerative therapy in mandibular Class II furcation defects with human mineralized bone allograft with or without bioabsorbable membrane provided additional benefits over open flap debridement alone. MBA was shown to improve bone fill significantly in Class II furcations. The benefits of the additional use of a GTR barrier could not be justified in this study because both MBA groups had comparable results. Future studies with larger sample sizes, strict case selections, and longer follow-ups are certainly encouraged.

\section{ACKNOWLEDGMENTS}

This study was partially supported by the University of Michigan Periodontal Graduate Student Research Fund and a gift grant from Zimmer Dental, Carlsbad, CA. In addition, the authors thank Zimmer Dental for donating materials. The authors also thank Dr. Paul Krebsbach, Department of Biologic and Materials Science, School of Dentistry, University of Michigan, and Brady West, Center for Statistical Consultation and Research, University of Michigan, for their guidance and helpful comments.

\section{REFERENCES}

1. Hamp SE, Nyman S, Lindhe J. Periodontal treatment of multirooted teeth. Results after 5 years. J Clin Periodontol 1975;2:126-135.

2. Carnevale G, Di Febo G, Tonelli MP, Marin C, Fuzzi M. A retrospective analysis of the periodontal-prosthetic treatment of molars with interradicular lesions. Int $J$ Periodontics Restorative Dent 1991;11:189-205.

3. Hellden LB, Elliot A, Steffensen B, Steffensen JE. The prognosis of tunnel preparations in treatment of Class III furcations. A follow-up study. J Periodontol 1989; 60:182-187.

4. Carnevale G, Pontoriero R, di Febo G. Long-term effects of root-resective therapy in furcation-involved molars. A 10-year longitudinal study. J Clin Periodontol 1998;25:209-214.

5. Pontoriero R, Nyman S, Lindhe J, Rosenberg E, Sanavi $F$. Guided tissue regeneration in the treatment of furcation defects in man. J Clin Periodontol 1987;14: 618-620.
6. Metzler DG, Seamons BC, Mellonig JT, Gher ME, Gray $\mathrm{JL}$. Clinical evaluation of guided tissue regeneration in the treatment of maxillary Class II molar furcation invasions. J Periodontol 1991;62:353-360.

7. Evans GH, Yukna RA, Gardiner DL, Cambre KM. Frequency of furcation closure with regenerative periodontal therapy. J West Soc Periodontol Periodontal Abstr 1996;44:101-109.

8. Murphy KG, Gunsolley JC. Guided tissue regeneration for the treatment of periodontal intrabony and furcation defects. A systematic review. Ann Periodontol 2003;8:266-302.

9. Jepsen S, Eberhard J, Herrera D, Needleman I. A systematic review of guided tissue regeneration for periodontal furcation defects. What is the effect of guided tissue regeneration compared with surgical debridement in the treatment of furcation defects? $J$ Clin Periodontol 2002;29(Suppl. 3):103-116.

10. Reynolds MA, Aichelmann-Reidy ME, Branch-Mays GL, Gunsolley JC. The efficacy of bone replacement grafts in the treatment of periodontal osseous defects. A systemic review. Ann Periodontol 2003;8:227-265.

11. Urist MR. Bone: Formation by autoinduction. Science 1965;150:893-899.

12. Schwartz Z, Somers A, Mellonig JT, et al. Ability of commercial demineralized freeze-dried bone allograft to induce new bone formation is dependent on donor age but not gender. J Periodontol 1998;69:470-478.

13. Günther KP, Scharf HP, Pesch HJ, Puh W. Osteointegration of solvent-preserved bone transplants in an animal model. Osteologie 1996;5:4-12.

14. Block MS, Degen M. Horizontal ridge augmentation using human mineralized particulate bone: Preliminary results. J Oral Maxillofac Surg 2004;62(Suppl. 2)67-72.

15. Block MS, Finger I, Lytle R. Human mineralized bone in extraction sites before implant placement: Preliminary results. J Am Dent Assoc 2002;133:1631-1638.

16. O'Leary TJ, Drake RB, Naylor JE. The plaque control record. J Periodontol 1972;43:38.

17. Miller SC. Textbook of Periodontia, 3rd ed. Philadelphia: Blackston; 1950:125.

18. Wang HL, O'Neal RB, Thomas CL, Shyr Y, MacNeil RL. Evaluation of an absorbable collagen membrane in treating Class II furcation defects. J Periodontol 1994; 65:1029-1036.

19. Silness J, Löe H. Periodontal disease in pregnancy. II. Correlation between oral hygiene and periodontal condition. Acta Odontol Scand 1964;22:121-135.

20. Löe H. The Gingival Index, the Plaque Index and the Retention Index Systems. J Periodontol 1967;38(Suppl.): 610-616.

21. Huang L-H, Neiva RF, Giannobile W, Wang H-L. The effect of platelet-rich plasma on the coronally advanced flap root coverage: A pilot human trial. $J$ Periodontol 2005;76:1768-1777.

22. Cury PR, Sallum EA, Nociti FH Jr., Sallum AW, Jeffcoat MK. Long-term results of guided tissue regeneration therapy in the treatment of Class II furcation defects: A randomized clinical trial. $J$ Periodontol 2003;74:3-9.

23. Paul BF, Mellonig JT, Towle HJ 3rd, Gray JL. Use of a collagen barrier to enhance healing in human periodontal furcation defects. Int J Periodontics Restorative Dent 1992;12:123-131.

24. Kenney EB, Lekovic V, Elbaz JJ, Kovacvic K, Carranza FA Jr., Takei HH. The use of a porous hydroxylapatite 
implant in periodontal defects. II. Treatment of Class II furcation lesions in lower molars. $J$ Periodontol 1988;59:67-72.

25. Gantes B, Martin M, Garrett S, Egelberg J. Treatment of periodontal furcation defects. (II). Bone regeneration in mandibular class II defects. J Clin Periodontol 1988;15:232-239.

26. Couri CJ, Maze GI, Hinkson DW, Collins BH 3rd, Dawson DV. Medical grade calcium sulfate hemihydrate versus expanded polytetrafluoroethylene in the treatment of mandibular Class II furcations. J Periodontol 2002;73:1352-1359.

27. Caffesse RG, Smith BA, Duff B, Morrison EC, Merrill D, Becker W. Class II furcations treated by guided tissue regeneration in humans: Case reports. J Periodontol 1990;61:510-514.

28. Lekovic V, Kenney EB, Kovacevic K, Carranza FA Jr. Evaluation of guided tissue regeneration in Class II furcation defects. A clinical re-entry study. J Periodontol 1989;60:694-698.

29. Calongne KB, Aichelmann-Reidy ME, Yukna RA, Mayer ET. Clinical comparison of microporous biocompatible composite of PMMA, PHEMA and calcium hydroxide grafts and expanded polytetrafluoroethylene barrier membranes in human mandibular molar Class II furcations. A case series. J Periodontol 2001; 72:1451-1459.

30. Alpar B, Leyhausen G, Gunay H, Geurtsen W. Compatibility of resorbable and nonresorbable guided tissue regeneration membranes in cultures of primary human periodontal ligament fibroblasts and human osteoblast-like cells. Clin Oral Investig 2000;4:219225.

31. Lekovic V, Camargo PM, Weinlaender M, Vasilic N, Aleksic Z, Kenney EB. Effectiveness of a combination of platelet-rich plasma, bovine porous bone mineral and guided tissue regeneration in the treatment of mandibular grade II molar furcations in humans. J Clin Periodontol 2003;30:746-751.

32. Levine HL, Stahl SS. Repair following periodontal flap surgery with the retention of gingival fibers. J Periodontol 1972;43:99-103.

33. Caton J, Nyman S, Zander H. Histometric evaluation of periodontal surgery. II. Connective tissue attachment levels after four regenerative procedures. J Clin Periodontol 1980;7:224-231.

34. Schallhorn RG, McClain PK. Combined osseous composite grafting, root conditioning, and guided tissue regeneration. Int $J$ Periodontics Restorative Dent 1988;8(4):8-31.

35. Lekovic V, Kenney EB, Carranza FA Jr., Danilovic V. Treatment of Class II furcation defects using porous hydroxylapatite in conjunction with a polytetrafluoroethylene membrane. J Periodontol 1990;61:575-578.

36. Anderegg CR, Martin SJ, Gray JL, Mellonig JT, Gher $M E$. Clinical evaluation of the use of decalcified freezedried bone allograft with guided tissue regeneration in the treatment of molar furcation invasions. J Periodontol 1991;62:264-268.

37. Wallace SC, Gellin RG, Miller MC, Mishkin DJ. Guided tissue regeneration with and without decalcified freeze-dried bone in mandibular Class II furcation invasions. J Periodontol 1994;65:244-254.
38. Wang HL, Burgett FG, Shyr Y, Ramfjord S. The influence of molar furcation involvement and mobility on future clinical periodontal attachment loss. J Periodontol 1994;65:25-29.

39. Demolon IA, Persson GR, Ammons WF, Johnson RH. Effects of antibiotic treatment on clinical conditions with guided tissue regeneration: One-year results. $J$ Periodontol 1994;65:713-717.

40. Becker W, Becker BE, Berg L, Prichard J, Caffesse R, Rosenberg E. New attachment after treatment with root isolation procedures: Report for treated Class III and Class II furcations and vertical osseous defects. Int $J$ Periodontics Restorative Dent 1988;8(3):8-23.

41. Jepsen S, Heinz B, Jepsen K, et al. A randomized clinical trial comparing enamel matrix derivative and membrane treatment of buccal Class II furcation involvement in mandibular molars. Part I: Study design and results for primary outcomes. $J$ Periodontol 2004;75:1150-1160.

42. Bowers GM, Schallhorn RG, McClain PK, Morrison GM, Morgan R, Reynolds MA. Factors influencing the outcome of regenerative therapy in mandibular Class II furcations: Part I. J Periodontol 2003;74:1255-1268.

43. Gottlow J, Nyman S, Lindhe J, Karring T, Wennstrom $\mathrm{J}$. New attachment formation in the human periodontium by guided tissue regeneration. Case reports. $J$ Clin Periodontol 1986;13:604-616.

44. Zappa U, Grosso L, Simona C, Graf H, Case D. Clinical furcation diagnoses and interradicular bone defects. $J$ Periodontol 1993;64:219-227.

45. Andersson B, Bratthall G, Kullendorff B, Grondahl K, Rohlin M, Attstrom R. Treatment of furcation defects. Guided tissue regeneration versus coronally positioned flap in mandibular molars; a pilot study. J Clin Periodontol 1994;21:211-216.

46. Black BS, Gher ME, Sandifer JB, Fucini SE, Richardson AC. Comparative study of collagen and expanded polytetrafluoroethylene membranes in the treatment of human Class II furcation defects. $J$ Periodontol 1994;65:598-604.

47. Steinberg AD, LeBreton G, Willey R, Mukherjee S, Lipowski J. Extravascular clot formation and platelet activation on variously treated root surfaces. J Periodontol 1986;57:516-522.

48. Haney JM, Nilveus RE, McMillan PJ, Wikesjö UM. Periodontal repair in dogs: Expanded polytetrafluoroethylene barrier membranes support wound stabilization and enhance bone regeneration. J Periodontol 1993;64:883-890.

49. Postlethwaite AE, Seyer JM, Kang AH. Chemotactic attraction of human fibroblasts to type I, II, and III collagens and collagen-derived peptides. Proc Natl Acad Sci USA 1978;75:871-875.

50. Bunyaratavej P, Wang HL. Collagen membranes: A review. J Periodontol 2001;72:215-229.

Correspondence: Dr. Hom-Lay Wang, Department of Periodontics/Prevention/Geriatrics, University of Michigan School of Dentistry, 1011 N. University Ave., Ann Arbor, MI 48109-1078. Fax: 734/936-0374; e-mail: homlay@ umich.edu.

Accepted for publication August 27, 2005. 